\title{
An Opportunities-Based Approach to Mitigating Risks Associated with Infrastructure Development Projects
}

\section{Don Messerschmidt}

Abstract. 'Risk' is a major point of focus in the literature on resettlement and reconstruction associated with the impacts of major infrastructure development on project affected individuals and families. Previous approaches to risk appear to emphasize the negative consequences of development, and it is no wonder then that project affected people often emphatically resist development and change. This paper proposes that a more pro-active, positive opportunities and benefits approach be taken in dealing with resettlement and reconstruction associated with large scale infrastructure projects. The discussion is focused on the eight 'risk factors' (or 'opportunity factors'?) listed in the well known 'Impoverishment Risk and Reconstruction' (IRR) Model. Three more such factors are added to the list based on field experience in South Asia. The point is that by emphasizing the potential opportunities and benefits, project affected people are more likely to be supportive of projects that may disrupt their lives.

Key words: Resettlement, opportunities, risk, IRR model, South Asia, infrastructure development

$\mathbf{T}$ his paper reviews and builds upon the landmark collection of studies edited by Michael M. Cernea and Christopher McDowell in Risks and Reconstruction: Experiences of Resettlers and Refugees (2000). ${ }^{1}$ The purpose here is to discuss risks and opportunities in light of the well known 'Impoverishment Risk and Reconstruction' (IRR) Model with additional discussion and suggestions based on lessons learned from infrastructure development in the field. Ultimately, it is to recommend a more positive approach to risk abatement, one that focuses first and foremost on the opportunities and benefits present. If project affected individuals and families were more aware from the start of the opportunities and potential benefits that attend forced resettlement, they would be more likely to feel positively about change and towards projects that otherwise disrupt their lives. It is hoped that readers familiar with the IRR Model's risk-based approach will consider modifying how they use it reflecting the more pro-active and positive opportunities-based approach suggested here. In this article the eight risk factors of the IRR model remain the same; with the addition of three more based on the author's development experiences in Nepal, Bhutan and Pakistan.

The bulk of this paper is adapted from an earlier discussion in the Prologue to the gazetted 2001 Manual for Public Involvement in the Environmental Impact Assessment (EIA) Process of Hydropower Projects produce by the Department of Electricity Development (DOED) of Nepal in collaboration with the US Agency for International Development (USAID) and International Resources Group (IRG). The manual was written by the author in association with Bharat Mani Sharma.

The paper begins with fundamental definitions and briefly raises gender issues, then launches into the main discussion of the opportunities-based approach to mitigating risk.

\section{Definition}

Public involvement in association with hydropower development projects, and others, is all about opportunity and risk.

Public involvement in the context of socioeconomic, cultural and Environmental Impact Assessment is defined as the active participation of people in appraising, planning, decision-making, evaluating and establishing mitigation associated with the impacts of development on society, economy and culture and on the physical and biological environment. Public involvement works best when it addresses the opportunities that arise, which are then taken up and built upon to avert or ameliorate risk.

Opportunity in this context refers to an advantageous circumstance or set of circumstances of potentially positive benefit to project affected persons or families; i.e., favorable, appropriate, helpful or fortunate outcome/s of some project activity, upon which a positive response may bring social, economic or cultural gain or benefit. On major infrastructure development projects it implies identifying positive actions to ameliorate risk through proactive development and reconstruction. (Note, however, that the economist's concept of 'opportunity cost' is a type of risk, therefore not what is meant here.)

Using a positive and empowering approach that seeks and acts upon opportunities arising will diminish both the amount of risks and cost involved, and will enhance public involvement in positive ways.

Risk refers to a kind of hazard or threat (real or perceived) that may arise as a result of the project development or activity. 
The potential risks from hydropower and other infrastructure developments are many - e.g., loss of property or other resources through displacement; decay of social cohesion; reduced economic stability; threat to cultural integrity; degradation of physical infrastructure; reduction of biodiversity; deterioration of health, education and other social rights and services; and so forth (including risky 'opportunity costs').

Socio-economic and cultural assessment should deal with both risks and opportunities, as they arise as the impacts of project development. To focus largely or exclusively on risks, however, is short-sighted, creates dependencies and is dis-empowering. I advocate a pro-active/ opportunities for success approach to public involvement.

Just how opportunities and risks are identified in infrastructure development inevitably influences major decisions in project planning and implementation, and has major impacts on local people. Potential opportunities and risks are inevitably among the topics of discussion at public hearings and workshops. Providing the public the opportunity to address the issues, to discuss public needs and concerns, and to work in partnership with developers and agencies to respond together to the impacts of development, will all go a long way towards assuring good outcomes.

On hydropower development projects and other large development works, public representatives on stakeholder committees should be involved directly in identifying reasonable opportunities to ameliorate the risks that inevitably arise. It must be emphasized, however, that while stakeholder committees can play important roles as representatives, advocates and spokespersons for the general public, risks to the public that arise from project developments are not easily alleviated with one-time or single element solutions, nor by single actors or agencies. The use of multiple methods for engaging the public, for addressing opportunities to ameliorate risks and mitigate adverse impacts, in pro-active ways, is recommended.

To the degree that a good public involvement and publications relations program can turn potentially negative reactions to change into positive reactions, project development will run more smoothly as compared with projects where public involvement is minimal and public relations are poor.

\section{A Note on Gender and Risk}

It is well known that women and children tend to suffer the adverse effects and impacts of development more severely than men.

Project proponents, planners, researchers, agency staff and other stakeholders should be very aware of gender discrimination and sensitivities. It is women who hold critical roles in family affairs, community activities and resource management. To avoid minimizing gender concerns in public activities, gender awareness must be a top priority.

Just as men as individuals suffer less from the disruption and displacement that typically attends project development, men as a group fare better also, when compared with the very poor, with women and with other vulnerable or marginalized groups (such as indigenous and tribal peoples). In short, men tend to fare better than others in the face of social and economic change.

There are several reasons for this, but the basic fact is related to the typical conditions of illiteracy, poverty and powerlessness or marginalization that exist among women and other vulnerable people. This fact alone encourages us to put gender at the top of the list - so that gender and socio-economic vulnerability will be considered in all public involvement activities, both in the choice of individuals to be addressed and to serve as representatives of others (e.g., on stakeholder committees) and in the choice of issues to address.

\section{The Components of Risk, and Opportunities to Mitigate Them}

A useful tool for anticipating and managing risk has recently been developed called the 'Impoverishment Risk and Reconstruction (IRR) Model (Cernea and McDowell 2000:Ch.1). This model is designated to point out the reality of what can go wrong in the context of development and to discuss ways to deal with it. On hydropower projects, the displacement of people, households and communities is a central issue, and this is reflected in the model.

The IRR model has four functions: (1) predication, (2) diagnosis, (3) problem-resolution, and (4) research. The authors of the model have identified eight risk factors dealing with land, shelter, employment, social change, social cohesion, health, nutrition and common resources. To that list I have added three more - education, local infrastructure and cultural heritage, based on the Nepal experience with large scale infrastructure development projects.

By this discussion, I propose modifying the IRR model's emphasis on 'risks' to deal more directly, proactively and positively with predicting, diagnosing, problem-resolving and researching 'opportunities' and 'benefits' that accrue from resettlement and change.

Note that much of the discussion of opportunities around the original eight IRR model factors, below, is paraphrased from the original, with some adaptation and modification reflecting the Nepal experience. 
BOX 1

Opportunities and Risks in Infrastructure Development: Environmental, Socio-Economic and Cultural Factors

Major infrastructure development projects (hydropower, roads and other) are typically designed with great attention to the technical aspects, but often with less concern for the inevitable social development and environmental issues. Project impacts are sometimes considerable and change may be positive or negative. In less developed countries, awareness and appreciation for both the opportunities and the risks involved are often beyond the comprehension of local people. The new construction may be greeted, therefore, with high expectations and enthu-siasm, or with concern, anxiety, suspicion or resistance.

In the literature on risks and reconstruction, Michael M. Cernea, Christopher McDowell and their colleagues discuss eight principle categories or areas of risk (see Risks and Reconstruction, 2000): landlessness, joblessness, homelessness, marginali-zation, food insecurity, increased morbidity and mortality, loss of access to common property assets, and community disarticulation. All are presented as 'risks', in the negative sense of loss. Certainly, risks are there, but based on field experience in South Asia I propose rephrasing the approach to emphasize potentially positive opportunities and benefits (over risks), and to increase the list to 11 factors, as follows:

\begin{tabular}{ll|l|l}
\hline \multicolumn{1}{c|}{ Categories } & \multicolumn{1}{c}{ Opportunities } & \multicolumn{1}{c}{ Risks } \\
\hline 1. $\quad$ Land & Resettlement & Landlessness \\
\hline 2. $\quad$ Shelter & House reconstruction & Homelessness \\
\hline 3. $\quad$ Employment & Jobs & Joblessness \\
\hline 4. $\quad$ Social Change & Social inclusion & Marginalization \\
\hline 5. $\quad$ Social Cohesion & Networking, community-building & Social dysfunction \\
\hline 6. $\quad$ Health & Improved health care & Increased morbidity \\
\hline 7. $\quad$ Nutrition & Adequate nutrition & Food insecurity \\
\hline 8. $\quad$ Common Resources & $\begin{array}{l}\text { Restoration of community resource assets } \\
\text { and services }\end{array}$ & $\begin{array}{l}\text { Loss of access to or denigration of } \\
\text { common property resources }\end{array}$ \\
\hline 9. $\quad$ Education & New or improved school opportunities & Children's education loss \\
\hline 10. Infrastructure & $\begin{array}{l}\text { Rebuilding or strength-ening } \\
\text { infrastructure }\end{array}$ & Infrastructure failure \\
\hline 11. Cultural heritage & $\begin{array}{l}\text { Saving, protecting or re-siting cultural } \\
\text { artifacts }\end{array}$ & Heritage degradation or loss \\
\hline
\end{tabular}

\section{Land: Land-Based Resettlement vs Landlessness}

Landlessness results from the expropriation of land for project use, thus removing the main foundation upon which people's productive systems, commercial activities and livelihoods are based. This is the principal form of decapitalization and pauperization of displaced people, as they lose both natural and manmade capital.

Providing alternative land and resources, at or near the resettlement site, is one solution to landlessness. But, resettlement must also take into account other associated factors, including socioeconomic and cultural traditions and needs of the resettled people as they perceive them. Where new and potentially more productive land can be made available to project affected families, this needs to be announced early on, and assiduously pursued as a desired outcome. If in agricultural communities no land or insufficient land is available, opportunities for alternative employment must be pursued (see \#3: Employment).

\section{Shelter: House Reconstruction vs Homelessness}

Loss of shelter tends to be only temporary for many resettlers; but, for some, homelessness and a worsening of housing standard remains a lingering condition. In a broader cultural sense, loss of a family's individual home and of a group's cultural space tend to result in alienation and status deprivation.

The issue of homelessness is closely allied with that of landlessness, above (\#1). In some instances national law may make no provision for compensating for land to people displaced by development who have no legal title to the land (as in Nepal). Many people reside on common properties, and in some projects they have been compensated for their huts, thus 
indirectly for the trauma of displacement from the land.

The most vulnerable and marginal peoples suffer more under this category of risk than those who have legal title and/or financial security. However, shelter vs homelessness must be discussed among the people, and mutually satisfactory solutions must be sought to ameliorate this negative impact of development. People facing loss of shelter, or decline in housing standards, if fully engaged in discussions and solutions, are very capable of doing a great deal to turn this risk into an opportunity.

Housing for the very poorest displaced people, for example, should be an option. And, the design of shelter components - e.g., living quarters, kitchens, systems of sanitation and adjacent land - should be socially and culturally appropriate.

\section{Employment: Reemployment vs Joblessness}

The risk of losing wage employment due to disruption from development is very high, especially for those employed in enterprises, services or agriculture. Creating new jobs is a fundamental need, though it is often difficult and may require special investment. Unemployment or underemployment among resettlers often endures long after physical relocation has been completed.

Opportunities for employing locally displaced peoples should be sought both within the project itself, and within ancillary developments (industries or services that spring up to accommodate development needs and new markets, or which are otherwise found in the vicinity). The implementation of special training programs in job skills for gainful employment is recommended.

\section{Social Change: Social Inclusion vs Marginalization}

Marginalization occurs when families lose economic power and spiral on a 'downward mobility' path. Middle-income farm households do not become landless, they become small landholders. And, previously small shopkeepers and craftsmen caught in this downward spiral may be forced to downsize and slip below poverty thresholds. Many individuals cannot use their earlier acquired skills at the new location; human capital is thus rendered obsolete or inactive, or is lost (see \#3: Employment).

Economic marginalization is often accompanied by social and psychological marginalization, expressed by a drop in social status, in resettlers' loss of confidence in society and in themselves, a feeling of injustice and deepened vulnerability. The coerciveness of displacement and the victimization of resettlers tend to depreciate resettlers' self-image, and they are often perceived by host communities as a socially degrading stigma. Opportunities must be identified and taken advantage of in innovative ways, so as to turn such negative conditions into positive ones.

The use of 'appreciative' methods for selfconfidence building and positive are useful here. ${ }^{2}$ Community members, themselves, can recognize the issues and address them through community action if given encouragement and a forum in which to act selfconfidently. More advantaged groups, when faced with the further downward spiral of the marginalized people in their communities, can be encouraged to assist their less fortunate neighbors in various ways, to help raise the overall self-confidence and self-sufficiency of the entire community.

\section{Social Cohesion: Networking and Community Building vs Social Dysfunction $^{3}$}

Involuntary displacement tears apart the existing social fabric. It disperses and fragments communities, dismantles patterns of social organization and interpersonal ties; kinship groups become scattered as well. Life-sustaining informal networks of reciprocal help, local voluntary associations and self-organized mutual services are disrupted (see \#4: Social Change). The cultural significance of social space is also assaulted (see \#11: Cultural Heritage). Disruption in the socio-cultural foundations of a place results in a net loss of valuable 'social capital' that compounds the loss of natural, physical and human capital. The social capital lost through social disarticulation is typically unperceived and uncompensated by the programs causing it, and this real loss has long-term consequences.

The issue is compounded by the dual affects of difficult physical and psychological acclimatization. If displacement and resettlement involves moving to a radically new and different environment, for example, feelings of ennui and alienation may arise, as well as sickness compounded by change in climate. Some populations may have difficulty, for example, in moving from high, cool environments to hotter, lower elevations, or from dry locales to places with high rainfall and humidity.

As new communities emerge through resettlement, and new constellations of social, cultural and economic inter-linkages are established, new forms of social capital may emerge. It is important to recognize these, capture and utilize them to help fill the social gaps and cultural discontinuities that are created by disruption and displacement. This is another place where an appreciative approach to development can play a catalytic role. It is also where community-based organizations (CBOs) and nongovernment organizations (NGOs) can become fruitfully involved. 


\section{Health: Improved Health Care vs Increased Morbidity}

Population displacement often leads to serious declines in health levels. Displacement-induced social stress and psychological trauma are sometimes accompanied by the outbreak of relocation-related illnesses, particularly parasitic and vector-born communicable diseases, including sexuallytransmitted diseases. Given the temporary influx of male laborers typical to hydropower and other infrastructure development projects, STDs, HIV/ AIDS, etc., are common problems arising. Unsafe water supply and improvised sewage systems also increase vulnerability to epidemics and to chronic diarrhea and dysentery.

The weakest segments of society in terms of health are infants, children and the elderly; they are typically affected most negatively.

Experience clearly shows that special attention must be paid to the overall public health care issue. The local people, especially young females, should be informed of the problems that may arise when changes in population dynamics occur (e.g., an influx of male laborers). Increased prostitution is a typical social response to household economic stress and demographic upheaval; hence, women and girls, in particular, should be made aware through information and training of healthier alternative employment opportunities.

Similarly, health care facilities may have to be bolstered as the population changes with the influx of laborers, and as new sites are resettled. Typically, established facilities become overwhelmed by demand, and are found wanting (see \#10: Infrastructure).

Here, again, outside agencies, NGOs and others, can become usefully involved.

\section{Nutrition: Adequate Nutrition vs Food Insecurity}

Nutrition is a special case of health risk (\#6). Forced uprooting increases the risk that people will fall into temporary or chronic undernourishment, defined as calorie-protein intact levels below the minimum necessary for normal growth and work.

The provision of sufficient land, including farm and kitchen garden space at resettlement sites, is important. Special training and encouragement of individuals and households to use both new and relevant traditional skills in farming and livestock rearing for self-consumption (and for sale of excess production), for example, are important in assuring food security. Closely linked to this issue are \#1: Land, \#2: Shelter, \#d: Employment, \#5: Social Cohesion, and \#6: Health.

\section{Common Resources: Restoration of Community Resource Assets and Services vs Loss of Access to Common Property Resources}

For poor people, particularly the landless and assetless, loss of access to common property due to community relocation (i.e., loss of pasture, forested land, water bodies, fisheries, burial grounds, quarries, and so on) results in significant deterioration in income and livelihood levels. Typically, losses of common property assets are not compensated by governments. These losses are compounded by loss of access to some public services, such as schools (see \#9: Education; also \#11: Cultural Heritage).

This issue presents a particular challenge to developers. On one large hydropower project in Nepal, for example, developers set up a special program to compensate for common property resource loss (e.g., fishermen who lost their traditional fisheries trained and employed in a newly developed fish hatchery operation). On another project, irrigation infrastructure, electricity and roads, health posts and schools were improved as part of the project's compensatory package to the communities.

From the author's field experience in Nepal, Bhutan and Pakistan, the following three factors have been added to complement the 'Impoverishment Risk and Reconstruction' (IRR) Model. The amelioration of risks associated with each factor, and the identification of opportunities and alternative solutions were seen to be of critical importance in the larger framework of change induced by displacement and resettlement caused by infrastructure developments.

\section{Education: Creating New School Opportunities vs Children's Education Loss}

Displacement and relocation often interrupt schooling and, for some children, it means never returning to school. Children typically feel the brunt of displacement and resettlement more severely, though less obviously, than their elders. And, typically, women, mothers and girls suffer more greatly than men, fathers and boys.

Following displacement, and as a result of drops in family income, many children are drafted directly into the labor force earlier than would have otherwise been the case. Young girls are often lured into socially unacceptable employment, away from school. Differences characteristic to particularly vulnerable groups calls for directly targeted responses. The children of the poor and other vulnerable groups are especially prone to disruptions in education. The challenge here is to work with local leaders and residents to help maintain some semblance of social 
and educational stability for the children and youth of the community.

Local NGOs and CBOs, in particular, should be encouraged to help identify opportunities and working with displaced children and youth in order circumvent the usual pitfalls that attend educational disruption and loss. Similarly, community leaders of both genders, including youth, should be fully engaged in identifying potential improvements in educational institutions and in accessing the opportunities that arise thereafter (see \#3: Employment, \#4: Social Change and \#5: Social Cohesion).

\section{Local Infrastructure: Rebuilding or Strengthening Infrastructure vs Infrastructure Failure}

Impacts from an influx of project laborers and growth of boom towns during project development often put severe pressures on existing local infrastructure. It is far too common for local people to begin feeling the disintegration of water supply systems, the decline of roads, and the failure of schools and health facilities to cope with increased numbers of people. Where changes such as these are unanticipated or not adequately addressed in advance, locals and new arrivals, alike, tend to suffer. And, where pre-existing but suddenly inadequate water systems fail under increased population pressure, serious health issues may arise - all the more so where crowding is caused by the sudden influx of laborers, and the presence of socially and economically disarticulated squatters (see factors \#4: Social Change, \#5: Social Cohesion and \#6: Health).

Where weaknesses in existing social service infrastructure are detected early on, developers and locals can work as partners to plan together to alleviate them. There are examples from hydropower projects where locals, largely on their own initiative and using their indigenous knowledge and intimate understanding of the resources and the environment, have worked successfully to lessen environmental breakdown (e.g., by planting trees on erosion prone roadsides, at virtually no cost other than time to the community or the developer).

\section{Cultural Heritage : Saving or Re-Siting Cultural Artifacts vs Heritage Destruction}

Development sites are sometimes richly endowed with cultural, religious or historical meaning or sanctity. These include temples and shrines, burial grounds and funeral ghats, spiritually endowed water sources, trees, forests or other landscape features, historic sites, and other culturally significant or aesthetically important locations. In the process of constructing hydropower project or other major development infrastructures and associated access roads, water impoundments, transmission lines, etc., sites of significant heritage or sanctity may be threatened. Such threats compound feelings of social disarticulation or dysfunction, and undermine good public relations (see \#5: Social Cohesion).

The alternative is to work with concerned peoples in local committees and with national heritage organizations to protect or to move and re-site sacred or historic artifacts, or to re-develop and reconsecrate them elsewhere, in culturally appropriate ways. Local people are the best judges of what is sacred, what is culturally or historically significant, and how such sites and resources are traditionally managed and used; thus, they are in the best position to know how to deal positively with potential threats to such sites. The public must be actively engaged in decisions about cultural heritage issues.

\section{Pro-Active Response to New Opportunities}

The amelioration of risk (through pro-action and the identification of opportunities in reconstruction) is a central point of concern in the public involvement process on development projects. In this regard, identification of the potential benefits to be realized in association with project sites is crucially important, and needs to be capitalized upon in positive ways. Local people need to be prepared for all foreseeable eventualities through increased access to information and to special counseling, training and other forms of empowerment.

For example:

- As rural communities become electrified, the need for house-wiring skills emerges. Everyone dreams of having electricity in their homes and businesses.

- Where social pressures and the impact of rising populations suddenly emerge, exposure to work-related hazards and accidents increases, along with social problems such as prostitution, alcoholism and gambling. Everyone feels the need for expanded public health facilities under such circumstances.

- Similarly, where the population is increasing, the demand for vegetable and cash crop production, animal husbandry, meat markets, food services and restaurants increases. There are many opportunities here for well prepared and progressive farmers and skilled entrepreneurs.

- Where an increased population is accompanied by a rise in the number of families with school-age children, demand for the building and management of schools and hostels, as well as adult skill training facilities will increase. These situations also reflect a rise in entrepreneurial opportunities. 
- Other potential opportunities include labor for construction works (e.g., roads, houses, water supply systems and other infrastructure development).

- All factors on the list are amenable to assistance by CBOs and NGOs working alongside and in collaboration with development projects and associated government agencies.

These are only a few examples of the many opportunities and issues that come up around project sites and resettlement areas. The list can be greatly expanded.

In all cases, two things need to happen to increase benefits and lower risks to local life and the economy: (1) local people need to be well informed ahead of time of potential opportunities arising and (2) they need access to the tools and skills necessary to take best advantage of new opportunities. This highlights all the more the need to train local men and women as semi-skilled laborers, entrepreneurs and paraprofessionals and to involve outside organizations in helping to make it happen.

Developers, government service agencies, NGOs and CBOs, alike, should plan ahead to identify the business and social service needs in order to work to assure that the local public is involved and prepared with the knowledge and skills necessary to meet them, before the lack of such skills creates new risks and unanticipated adverse impacts. Thus, Public Involvement must be opportunities-oriented, participatory and pro-active.

Don Messerschmidt is an anthropologist who has worked on hydropower, drinking water, groundwater and road development projects, as well as in natural resource management and community health programs. His consulting has taken him to Nepal, Bhutan, Pakistan, Indonesia and Vietnam, over a period of four decades. (He first worked in community development as an American Peace Corps Volunteer in Nepal in the early 1960s.) Dr Messerschmidt is the lead author of the Manual for Public Involvement in the Environmental Impact Assessment (EIA) Process of Hydropower Projects from the Department of Electricity Development (Nepal, 2001) and of the Reference Manual for Environmental and Social Aspects of Integrated Road Development from the Department of Roads (Nepal, 2003). He has published numerous articles on development in professional journals and books, and has served as Executive Editor of HydroNepal since its inception.

Corresponding address: dmesserschmidt@gmail.com

\section{Notes}

1 In particular, see Cernea's 'Risks, safeguards, and reconstruction: A model for population displacement and resettlement' (Ch.1, pp.11-55 in Risks and Reconstruction) and Cernea's 1997 paper on 'The risks and reconstruction model for resettling displaced populations' (in the journal World Development v.25, n.10, pp.156-1588).

2 The use of 'appreciative' methods refers to the strategies of 'Appreciative Inquiry' (AI) and 'Appreciative Planning and Action' (APA) that some development organizations and agents use in the context of participatory development. AI and APA are participatory processes especially useful for engendering a positive, empowering and equitable approach to the long-term opportunities for mitigating risks. They are typically low cost (and in some instances virtually no-cost), but boast a high success rate through a combination of partnership and self-help. For example, see 'Issues in participatory development: From participatory rural appraisal to Appreciative Planning and Action...' (Odell, 2001). For a review of AI processes and outcomes (with a comprehensive bibliography), see Messerschmidt (n.d.), 'Evaluating Appreciative Inquiry as an organizational transformation tool: An assessment from Nepal' (in press).

3 Cernea's original terminology here is 'Social Disarticulation'.

\section{References}

Cernea, M., 1997, 'The risks and reconstruction model for resettling displaced populations', World Development v.25, n.10, pp.156-1588.

Cernea, M., 200o, 'Risks, safeguards, and reconstruction: A model for population displacement and resettlement', Ch.1, pp.11-55, in M. Cernea and C. McDowell, eds., Risks and Reconstruction: Experiences of Resettlers and Refugees, Washington, DC: The World Bank.

DOED, 2001, Manual for Public Involvement in the Environmental Impact Assessment (EIA) Process of Hydropower Projects, Kathmandu: Department of Electricity Development.

DOR, 2003, Reference Manual for Environmental and Social Aspects of Integrated Road Development, Kathmandu: Department of Roads.

Messerschmidt, D., 2008, 'Evaluating Appreciative Inquiry as an organizational transformation tool: An assessment from Nepal', Human Organization, in press.

Odell, M.J., 2001, 'Issues in Participatory Development: From Participatory Rural Appraisal to Appreciative Planning and Action - A Personal Journey of Discovery', PD Forum Paper (www.pdforum.org/ odell14.html), Kathmandu: Habitat for Humanity Inter-national. 